\title{
On the Use and Potential of Behavioural Economics from the Perspective of Transport and Climate Change
}

\author{
Erel Avineri \\ A revised version of a paper accepted to a special issue of Journal of Transport Geography \\ (Theoretical Perspectives on Climate Change Mitigation in Transport).
}

\begin{abstract}
It can be argued that the main thinking in transport planning and policy making stem from neoclassical economics in which individuals are largely assumed to make rational, consistent, and efficient choices, and apply cognitive processes of decision making that maximise their economic utility. Research in behavioural sciences indicates that individuals' choices in a wide range of contexts deviate from the predictions of the rational man paradigm inspired the research agenda in the field of travel behaviour. New concepts and practices of government aim to apply some behavioural economics insights in the design of behavioural change initiatives and measures, an approach recently advocated in the US and the UK. This paper provides a brief review on the use and potential of behavioural economics from the perspective of transport and climate change, in two main contexts: travel demand modelling and design of behaviour change measures. The discussion of limitations and knowledge gaps associated with the implementation of behavioural economics to a travel behaviour context might contribute to the debate and help in defining research agenda in this area.
\end{abstract}

Keywords: Behavioural change, Behavioural economics, Travel behaviour, Nudge

\section{Introduction}

Travel behaviour has been an area of great interest to practitioners and researchers ever since the introduction of transport modelling in the 1950s. The travel choices made by individuals - such as mode choices, route choices and time choices - all have a direct impact on the performance of transport systems and networks.

Increasing awareness that our travel behaviour generates positive and negative effects on our individual and collective wealth, health and well-being extended the application of travel behaviour research to a wider context. A range of negative and positive externalities associated with travel choices are been considered by transport researchers and practitioners more seriously than ever; such are, for example, transport-related $\mathrm{CO}_{2}$ 
emissions which contribute to the problem of climate change (Chapman, 2007). In the European Union, the transport sector (excluding air travel) represents $18 \%$ of all $\mathrm{CO}_{2}$ emissions (EEA, 2011, p.36). Considerable reductions in emissions are required from the transport sector to meet environmental targets set by international organisations (such as UNFCCC, the United Nations Framework Convention on Climate Change), but it has been largely recognised that such targets cannot be fully met without substantial change to travel demand.

Modelling and understanding of travel behaviour have been long been applied in the field of transport, addressing three main goals: (i) to provide theoretic insights on why and how people travel; (ii) to estimate the properties of attributes associated with the travel choices (e.g. travel time, travel cost) and with travellers' characteristics (e.g. socio-demographics) in order to predict their future behaviour; and (iii) to test the possible outcomes of proposed infrastructure or policy changes, with an ultimate goal of making effective improvements to social and individual wellbeing through the development and implementation of a range of design, planning and policy measures.

This paper provides a critical review of the theoretical and practical application of concepts and theories associated with the emerging field of behavioural economics in the context of travel behaviour and the major challenges associated with it - climate change being one of them. It addresses the potential contribution of behavioural economics to two different although linked applied fields of transport research: the modelling of travel choices and the design of behaviour change initiatives. This paper is not intended to be a systematic review of behavioural economics; it aims to report on a selective sample of concepts from this field that might be of specific relevance to those who are interested in its application to transport and climate change context (for a wider background to behavioural economics see Metclafe and Dolan, forthcoming, featured in this special issue). The paper concludes with the identification of several aspects that can be prioritized in the definition of research agenda in travel behaviour.

\section{Incorporating behavioural notions in the analysis and development of travel behaviour}

\subsection{A brief history of travel behaviour models}

Travel behaviour is seen by many as the physical outcome (or 'choice') exhibited by a traveller and captured by her revealed or stated preferences and actions. Travel behaviours commonly addressed by researchers and practitioners are route choices, mode choices, destination choices, and choices associated with the time to travel. Other actions that can be considered as travel behaviours might include vehicle purchasing and ownership (i.e. number and type of cars owned by household); acquisition of driving license and responses to its control and disposal; parking choices; and pooling or sharing travel arrangements. 
Micro-behaviours such as driving styles (e.g. speed, acceleration) are usually not associated with travel behaviour. Although it largely focuses on the aggregated behaviour of individuals, travel behaviour models and frameworks explore other levels of aggregation (e.g., household, organisation, community, and spatial units).

In most applied contexts of travel behaviour, the term is used to present the observed actions of travellers (as in the 'modelling' and 'prediction' contexts). The individual actions that are targeted by interventions and policy measures are also seen as 'behaviours'. It might be argued by some researchers in the field of travel behaviour that the dynamic economic, cognitive, psychological and social processes that lead to travel choices should also be seen as important elements of travel behaviour, and therefore included in a wider definition of it. This argument could be related to the proposition of the behaviourism philosophy in psychology that all things that humans do can be regarded as behaviours. However in this paper we will apply the more common use of travel behaviour as a term representing observed physical actions.

In his review on transport models, philosophy and language, Timms (2008) (following Pas, 1990), distinguishes two main eras of transport modelling: (i) A social physics era (stretching from the 1950s to the 1970s), characterised by the importation of analogies from traditional physics to transport modelling, and concerned primarily with the modelling of (aggregate) systems rather than people; and (ii) an economics era (stretching from the 1970s to the present day), which has been dominated by neoclassical economic concepts, focussing upon the representation of people as individual rational choice makers, interacting together to form a state of equilibrium.

The behavioural assumptions on travellers' choices, and their responses to policy interventions, can be traced back to economic theory and the paradigm of rational man. The development of travel behaviour models in the second era has been largely inspired by models of consumer choice; the principles of rational behaviour, such as individual's tendency to maximise her utilities were applied to traveller behaviour to simulate choices of destination, mode, route, and time. Although this modelling approach is based on statistical analysis demonstrating levels of association rather than behaviour notions, models of individual travel choice were regrettably termed 'behavioural' (Atkins, 1987). It was argued that this and other weaknesses in the 'traditional' models have had negative impacts efficiency of transport planning and policy making (e.g. Atkins, 1987). Gärling (1998) has made the observation that behavioural assumptions of mainstream travel behaviour models are almost always made without reference to existing theories in behavioural sciences (in particular psychology).

Ben-Akiva and Lerman (1985, p.32) describe the theory of choice as a collection of procedures that define the following elements: (i) decision maker, (ii) alternatives, (iii) attributes of alternatives, and (iv) a decision rule. The attractiveness of an alternative in the mind of the traveller is described as a vector of the attribute values (which is later reduced 
to a scalar, 'utility', as an index of the attractiveness of an alternative). If travellers are expected to act as rational human beings, and specifically to exhibit consistency and transitivity in their choices (ibid., p. 38), then the way alternatives and attributes are presented to the traveller, travellers' set of attitudes and beliefs, social norms and habits should not matter much to choice making, and individuals should not be affected by what might be considered as irrelevant context. However, emerging research findings in travel behaviour research provide evidence on the important roles such (and other) psychological and social factors have on travel behaviours.

According to a range of theories in social psychology, behaviour is determined by beliefs and attitudes rather than utilities. In recent reviews (Anable et al., 2006, Bamberg et al., 2010) it is argued that most of the psychological research on travel behaviour change has primarily been guided by two theories: the theory of planned behaviour (TPB) (Ajzen, 1991) and the norm-activation theory (Schwartz, 1977). According to TPB, the relative strengths of individual's intentions to perform alternative behaviours guide the choice between them, where the determinants of intended behaviour are a set of individual's beliefs: attitudes toward behaviour, subjective norms and perceived behavioural control. Norm-activation theory accounts for pro-social motives and allocates a central role to personal norms. Although attitudes and believes, and their role in decision making, are explored in the field of behaviour economics, most behavioural economics would not consider social psychology theories (such as TPB) appealing for it postulates a quite strong of rationality. Although neoclassical economics and social psychology have different views of choice making, rational behaviour, in its broad meaning, is still largely assumed by theories such as TPB and norm-activation theory: individuals faced with choices are assumed to perform a high-level cognitive process, a process that can be largely described as a planned and consistent. Recently there have been attempts to enhance the utility-based framework by accounting for latent factors such as perceptions, attitudes, norms, and decision protocols (Ben-Akiva et al., 2002; Abou-Zeid et al., 2012). Whilst TPB, which assumes behaviour is a product of intention, provides powerful explanation of behaviour in a wide range of contexts, it can be also argued that some behaviour occurs with little or no pre-planned intent. In that aspect behaviour can be seen as impulsive, habitual or emotional rather than planned (see, for example, Gärling et al., 1998).

\subsection{The relevance of behavioural economics to travel behaviour}

Research in behavioural sciences, especially cognitive psychology, indicate that individuals' choices in a wide range of contexts deviate from the predictions of rational behaviour. Some of these deviations are systematic, consistent, robust and largely predictable (Tversky and Kahneman, 1974; Kahneman and Tversky, 1979). 
Although many might see the roots and origins of behavioural economics in the work of Herbert Simon on bounded rationality and the studies of cognitive psychologists, such Amos Tversky and Daniel Kahneman, there have been influences from behavioural sciences on economics through its development since the $18^{\text {th }}$ century. Actually, at the classical period (identified with the works of Adam Smith, David Ricardo, Thomas Malthus and John Stuart Mill), microeconomics was more closely linked to psychology. For example, Smith's Theory of Moral Sentiments (1759) proposed the incorporation of psychological insights into individual behaviour, including notions such as habits, customs, utility, fashion and concerns about social wealth, fairness and justice (see Ahraf et al., 2005). Although it took a separate path at the neoclassical period (neoclassical economics and psychology have different views of choice making), economics has continued to flirt with behavioural sciences to the present day.

Herbert Simon stressed the importance of emotion as a determinant of behaviour and choice making, taking into account intuition and heuristics in decision making processes, and coined the term 'bounded rationality'. Simon (1956) created doubt on the use of economic theories of rational behaviour as a basis for explaining the characteristics of human rationality. He argued that the behaviour of an individual should be understood relative to their environment, and that "no utility function needs to be postulated for the organism, nor does it require any elaborate procedure for calculating marginal rates of substitution among different wants". Recent research in behavioural sciences indicates that individuals' choices in a wide range of contexts deviate from the predictions of the rational man paradigm - inspiring research on travellers' bounded rationality (see, for example, the review of so-called 'cognitive anomalies' in McFadden, 1999).

General economics can be defined as "a science which studies human behaviour as a relationship between ends and scarce means which have alternative uses" (Robbins, 1932) and one might wonder what makes behavioural economics a unique field. It is important to acknowledge that behavioural economics is not a homogenous field that one can demarcate straightforwardly and that different academics have different opinions as to what counts as behavioural economics. One way of defining it is to contrast it with neoclassical economics. Laibson and Zeckhauser (1998) see behavioural economics as a field which is "skeptical of perfect rationality, emphasises validation of modelling assumptions, integration of microlevel data on decisions (including experimental evidence), and adoption of lessons from psychology". As one of the aims of social sciences is to provide explanations and predictions of human behaviour, behavioural economics (being a discipline of economics, which by itself is a branch of social sciences) aims to "increase the exploratory and predictive power of economic theory by providing it with more psychologically plausible foundations." (Angner and Loewenstein, 2010).

Over the last few decades the field of behavioural economics has generated a large body of conceptual and empirical models that would be relevant to the context of travel behaviour, 
and it is not possible to cover all (or even most) of them. However, to provide a brief overview of some of its key findings of behavioural economics, and to highlight the main shortfalls in the neoclassical model of human behaviour, it might be useful to refer to the following key principles identified by the new economics foundation (Dawnay and Shah, 2005): (i) other people's behaviour matters; (ii) habits are important (iii) people are motivated to 'do the right thing'; (iv) people's self-expectations influence how they behave; (v) people are loss-averse and hang on to what they consider 'theirs'; (vi) people are bad at computation when making decisions; and (vii) people need to feel involved and effective to make a change. The examples presented in the next section illustrate how some of the above concepts have been explored and incorporated to travel behaviour models. These examples tend to relate to several specific areas of research that attract relatively high interest from the travel behaviour community.

In the last decade there has been a surge of interest in behavioural economics; several books on behavioural economics, or fields related to it, and their applications in explaining human behaviour in a range of contexts introduced the general principles of behavioural theories to explain economic behaviours as well as applications to a range of contexts to the broad public (and some have became best-sellers), among them are Thaler and Sunstein's 'Nudge' (2008); Ariely's 'Predictably Irrational' (2008); Shiller's 'Irrational Exuberance' (2000) Akerlof and Shiller's 'Animal Spirits' (2009), and Cialdini's 'Influence' (2001). Perhaps some of the catalysts to public's interest in bounded rationality in decision making are the behaviour of financial markets (such as the 1987 stock market crash) and the ongoing economic crisis, where not only the 'general public', but also experts, financial organisations governments suffer from bounded rationality in making economic decisions.

Recent work in travel behaviour research integrates insights from psychology with neoclassic economic theory in order to improve the explanation and prediction of the behaviour of travellers; parallels between the aims of and processes applied in behavioural economics and recent advances in travel behaviour can be observed, although travel behaviour research make few direct references to behavioural economics. Although they share some similar insights with research studies in behavioural economics, the incorporation of behavioural notions into travel behaviour models, and the development of new frameworks that apply conceptual models from behavioural sciences have not directly evolved from behavioural economics; recent thinking in travel behaviour mainly linked to works in psychology and sociology that has also inspired behavioural economists. For example, the deviations of travel choices under risk and uncertainty from the predictions of rational models has applied cognitive models of decision-making developed by psychologists such as Tversky and Kahneman - although the same models applied by behavioural economists to explain systematic errors made by market players that lead to the creation of market inefficiencies. However, as there are so many similarities and parallels between the behavioural factors emphasised in behavioural economics and the recent research interests in travel behaviour, behavioural economics might provide a useful conceptual framework to 
the study of travel behaviours that are not purely rational. Evidence on systematic deviations from rational models have been known in some domains for quite some time (e.g. Simon, 1956), though the application in travel behaviour is more recent. Evidence on systematic deviations from rational models that have emerged from studies on consumer choice behaviour, financial behaviour, health behaviour, and energy consumption might be also relevant to travel behaviour researchers.

Parallel to the development of 'traditional' economic models of travel behaviour in the second half of the 'economic era', there have been a growing interest and an emerging body of work seeking to understand behaviour by incorporating insights from behavioural sciences into travel behaviour research, giving more weight to what are sometimes called 'irrational' motives and behaviours, leading to the development of new, and sometimes alternative, modelling approaches. Recent developments in travel behaviour research suggest incorporating behavioural notions in travel behaviour models in order to improve understanding and predicting of behaviour, and to improve the success of transport planning and policy making processes that apply such models (see reviews by Gärling, 1998; McFadden, 1999). Behavioural notions that have been incorporated in travel behaviour models might include attitudes and believes, social and cultural norms, habits, determining human behaviour. Moreover, it has been argued that decision rules might not be in-line with the assumptions of rational behaviour, leading to perceptions and behaviours that systematically deviate from the predictions of rational choice models. A modelling framework that attracts attention from the research community in the last two decades is activity-based travel demand modelling, which applies time-geography theory and the personal (and social) constraints and opportunities related to one's need to participate in activities associated with travel (Axhausen and Gärling, 1992).

\subsection{Links between findings at travel behaviour research and behavioural economics: $A$ selection of evidence and examples}

A cognitive modelling approach that has attracted relatively high level of interest among travel behaviour researchers is prospect theory (PT, Kahneman and Tversky, 1979), and its further extension, known as cumulative prospect theory (CPT, Tversky \& Kahneman, 1992). Although been developed by psychologists, its main applications are in the study of economic decisions, and it has become one of the key areas of behavioural economics. Through a series of experiments, Tversky and Kahneman found strong evidence of systematic deviations from normative models of risky choice making. This has led them to the development of a descriptive model of choice making, which captured the observed behaviour of individuals in settings that involve risky choices.

One of the key observations of prospect theory, called loss aversion (or gain-loss asymmetry) refers to the fact that people tend to be more sensitive to negative impacts, or 
losses, than to positive impacts, or gains (this is considered as one of the key principles of behavioural economics, according to Dawnay and Shah, 2005 and others). Parallels in travel behaviour can be observed. For example, the way travellers perceive and evaluate travel choices is much influenced by the context in which travel information is being presented to them; travellers exhibit aversion to loss and have a strong tendency to avoid choices associated with losses (Avineri and Prashker, 2004; van de Kaa, 2010a; Rose and Masiero, 2010).

Another key principle of behavioural economics is that people are bad at computation when making decisions; in particular "they cannot calculate probabilities well and worry too much about unlikely events" (Dawnay and Shah, 2005). This can be illustrated by another observation of PT/CPT (Kahneman and Tversky, 1979): decision makers tend to overweight small probabilities, which implies that they make riskseeking choices when offered low probability high-reward lotteries. At the same time the behaviour of people exhibit underweighting of high probabilities (also known as 'the certainty effect'). Empirical studies of travel behaviour have generally confirmed that small probabilities of outcomes associated with travel choices are overweighed and large probabilities are underweighted (e.g., Avineri and Prashker, 2004). Certainty effects were accounted for the impact on the evaluation of the urban commute experience by public transport passengers (Li, 2003).

As many of the behavioural assumptions and paradigms applied in travel behaviour modelling have emerged from the normative models challenged by the descriptive model of $\mathrm{PT}$, it is not surprising that transport researchers where interested to revisit these assumptions and explore the potential of PT in providing alternative explanation and better prediction of travel choices. As a descriptive model that predicts choice under risk and uncertainty, PT has been seen as a relevant theoretical and empirical framework to explore the effect of travel time variability on travel choices (mainly route and departure time choice). As travel alternatives carry both positive and negative components of utilities and values, their attributes can be framed as 'gains' or 'losses', making the concept of referencedependent preferences and loss aversion relevant to travel choices.

The result is a growing body of recent studies that apply PT and its extension, CPT, or some of their notions (specifically gain-loss asymmetry) to model a variety of travel choicedimensions such as route choices (e.g. Avineri and Prashker, 2004; Viti et al., 2005; Gao et al., 2010), departure time choices (Senbil and Kitamura, 2004; Jou et al., 2008), choice of bus lines (Avineri, 2004), and choices whether or not to perform a given trip (Schwanen \& Ettema, 2009). Several papers provide reviews of prospect theoretic contributions in understanding traveller behaviour (e.g. Avineri and Bovy, 2008; van de Kaa, 2010b; Li and Hensher, 2011). At the same time, some critical views discussed the shortcoming and limitations in the modelling of travel choices (e.g., Timmermans, 2010).

There have been several attempts to further apply PT and CPT to improve network equilibrium models, substitute for decision rules, and examine the effect of the reference 
point value on such equilibrium (e.g. Avineri, 2006; Connors and Sumalee, 2009; Tian et al., forthcoming). However most of this work in this field is theoretical by nature and the functional forms of PT/CPT apply parameter values that were obtained through experiments in general, non-transport contexts (such as Tversky \& Kahneman, 1992).

Other than PT and CPT, there have been so far only limited attempts to apply insights from cognitive psychology and behavioural economics in travel behaviour models. However there is a body of evidence showing that people are poor at computation when making travel choices, and in some contexts the systematic deviations from the rational models of choice exhibited in their preferences and choices might be explained by descriptive models studied by behavioural economists and cognitive psychologists. For example, a general observation about behaviour that deviate from rationality is that people often disregard the different denominators of the given rates, and they average them via the simple arithmetic mean which is based on uniformity and symmetry instead of a weighted mean (Falk and Lann, 2008). Evidence of this and other size-biased sampling in economic decisions and other areas are well known. Applying such intuitive judgment (using arithmetic mean instead of self-weighted mean in the interpretation of bus timetables) people might misinterpret or misperceive headway-type information and tend to underestimate their anticipated waiting time (Avineri, 2004), a finding that might contribute to the understanding of the general observation that public transport passengers generally overestimate their experienced waiting time (e.g. Mishalani et al., 2006).

Another example of a systematic deviation from rational decision making is associated with choice behaviour in repeated choices settings in which the decision maker relies on feedback from her past experience (rather than rely on description of choice attributes). The sampling mechanisms applied by decision makers in repeated choices situations, and perception biases in learning from experience might lead to the so-called payoff variability effect: an increase in the variance of the payoff distribution of the possible outcomes appears to move aggregate choice behaviour towards random choice (e.g., Erev and Barron, 2005). In a route choice context it has been observed that increasing travel time variability of a route with a high expected travel time increases its popularity, and generally reduces travellers' tendency to select risky alternatives and slows down their learning process - a behaviour that is not consistent with the assumption of transitivity and the predictions of rational models (Avineri and Prashker, 2005; Ben-Elia et al., 2008). Incorporating the notion of payoff variability in route choice models could improve their prediction value.

One of the key principles of behaviour economics is that other people's behaviour matters: "people do many things by observing others and copying; people are encouraged to continue to do things when they feel other people approve of their behaviour." (Dawnay and Shah, 2005). Social norms, social learning, social proof, social identity, pro-social behaviour and altruism are some of the concepts applied in social psychology to explain and predict how individual's decision making is influenced by others (or more accurately, by 
one's believes regarding others). There is a body of evidence to suggest that in social dilemma situations decision makers tend to take actions that are in the common interest provided that they expect others will also take some actions. Allowing for communications among experiment participants can result in increased level of cooperation (Ostrom et al., 1992).

The social dimension of decision making is of specific relevance and importance to choice making in a travel behaviour context. It is common to represent aggregated travel behaviour as a non-cooperative agents game, assuming travellers behaviour is selfish by nature. Social aspects of travel behaviour (such as social value orientation) are commonly omitted from the formal modelling process, quite often treated as (unbiased) random errors or qualitative caveats.

It is the interest of all if more people decide to travel in more efficient, sustainable and safe ways. However in many travel behaviour contexts there are conflicting individual and collective interests that can be framed as social dilemmas (thus the expected choice of a rational individual would be to "free-ride"). For example, choosing between commute by private car and bus is often framed as a social dilemma (e.g. Van Vugt et al., 1995, Kitamura et al., 1999; Sunitiyoso et al., 2011a). In the analysis of social interactions between travellers facing social dilemmas, Sunitiyoso et al. (2011a, 2011b) showed the existence of strategic behaviours that follow social learning models of confirmation (reinforcing behaviour if other group members have similar behaviour) and conformity (following the majority choice in the group).

There is growing interest in the study of social influence in the context of travel, mainly in activity-based modelling (see, for examples, Vovsha et al., 2003; Salvini and Miller, 2005; Goulias and Henson, 2006; Arentze and Timmermans, 2008). However, so far there has been only little application of socio-psychological aspects of choice behaviour in other types of travel behaviour models (such as equilibrium models, microsimulations, and discrete choice analysis).

\section{Behavioural change: Applying insights from behavioural economics to a behaviour change context}

Concerns over climate change, air pollution, health and congestion on the road network, coupled with falling oil reserves, are leading governments to take action to change the way people travel. However, for a variety of reasons, not all countries are equally committed to behaviour change. This is partly because of different levels of awareness, lack of resources or limited political power. Behaviour change and climate change mitigation policies are made in political, economic, cultural and geographical contexts, largely different from one country to another. For example, there is a debate about the balance between the low 
emissions and high vulnerability of the developing world to climate change, compared to high emissions in the developed world, leading to arguments about climate justice and climate change migration (Liverman, 2008).

Individuals are being encouraged to travel in more efficient and sustainable ways. Behavioural change initiatives have been shaped by a wide range of theories and concepts that have emerged from economics, psychology, sociology, criminology, and more recently behavioural economics. Different approaches have been applied to encourage, enforce and nudge citizens to make choices that are better for them and society.

Alongside the 'hard' transport policy measures, such as economic interventions, changes to infrastructure, legislation and enforcement, which modify the objective environment (and considered by many as limiting their freedom to make travel choices), there is a growing interest in the design and implementation of a range of alternative or supplementary 'softer' interventions. Soft behavioural change interventions such as education, training and information provision, and mass-media persuasion (through advertising and the use of campaigns) have been successfully applied in a wide range of domains, among them public health, energy consumption, and transport - in which the approach is also known as 'smarter choices' (Cairns et al., 2008) or 'mobility management' (Taniguchi and Fujii, 2007). This approach has attracted increased attention from both transport policy makers and researchers in EU countries, Australia, Japan and elsewhere. Somewhat inspired by social psychology (although not applying systematic frameworks in the design and evaluation of measures), the UK Smarter Choices is a wide range of rather diverse measures including persuasive and information elements applied in workplace and school travel plans, personalised travel planning, and general marketing campaigns.

Of much relevance to the application of behavioural economics to behaviour change is the recent emergence of 'libertarian paternalism' (Thaler and Sunstein, 2003) and modern concepts (and practices) of government associated with it. According to this political philosophy, governments could seek to influence the behaviour of individual citizens in directions that will improve their lives, but at the same time aim to keep a range of options available for the public to choose from. Soft measures are very much in line with the concept of libertarian paternalism. They are commonly perceived by public and government as interventions that do not limit or enforce the choice; instead, they aim to influence travellers' choices by "altering their perceptions of the objective environment, by altering their judgements of the consequences associated with the use of different travel options, and by motivating and empowering them to switch to alternative travel options" (Bamberg et al., 2010).

The previous section described behavioural economics as an emerging body of work seeking to understand behaviour that deviates from the predictions of rational choice models by incorporating insights from behavioural sciences into economics, giving more weight to what are sometimes called 'irrational' motives and behaviours (Avineri and Goodwin, 2010). 
But its applications go beyond providing explanations and predictions of choice behaviours. The 'predicted irrationality' (a term coined by Ariely, 2008) of individuals could (and some argue - should) play a role in the design of behavioural change interventions. Thaler and Sunstein (2008) advocate the use of 'choice architecture' to influence behavioural change; they illustrate how 'nudges', small features designed in the environment of choice making, could help individuals to overcome cognitive biases, and to highlight the better choices for them (by helping the automatic system to make better decisions) and increase the effect of behavioural change - without restricting their freedom of choice, and without making big changes to the physical environment, the set of choices, or the economic attributes of the choices. Choice architecture may be perceived by policy makers as less controversial and cheaper than larger scale interventions, which might have contributed to its recent popularity.

It can be generally argued that choice architecture and other insights emerging from behavioural economics can inform the design of measures to effectively influence socioeconomic behaviour in a range of geographical and political contexts. However, the notion of libertarian paternalism and the application of soft measures would be particularly relevant to western, liberal democracies, such as the US (where is has been first popularised) or the UK. Jones et al. (2011) argue that in the UK the approach can be justified "on the basis of affording citizens greater choice and freedom from the state in the coproduction of personalized government service delivery".

Thaler and Sunstein (2008) review the use of nudges in the choice architecture of financial, marketing, public health, and energy consumption decisions. So far there has been only limited literature on the applications of behavioural economics to the design of behaviour change policies and initiatives in transport, and choice architecture has not been much applied and evaluated in this context; therefore, its effectiveness remains an open question. Following we illustrate how some of the insights from behavioural economics might be incorporated in the design of behaviour change measures, and some of the evidence emerging from recent research in this area.

Studies on the cognitive architecture of the mind (Fodor, 1983) suggest that is composed of an array of interacting, specialised subsystems with somewhat limited flows of intercommunication. Many perceptual and cognitive processes work independently of each other, specialise in processing specific inputs from the environment. Brain scientists and cognitive psychologists have discovered that the brain functions as if it had two systems of decision making; one is very fast and automatic, while the other one is reflective (Epstein, 1994). It appears that while the reflective system processes the information content, and applies rather systematic and rational 'algorithms', a parallel process takes place in our brain by the automatic system which processes the context of information - such as the visual environment of the main message, applies heuristic 'short-cuts', and attaches emotions and feelings. People are influenced by images, symbols and context, i.e. the 
manner in which information is being presented to them. For example, a textual message coloured in red would carry an additional connotation besides the text or numeric content.

If individuals are expected to act as rational human beings, and specifically to exhibit consistency and transitivity in their choices, then the way alternatives and attributes are presented to the traveller should not matter much, and individuals should not be affected by irrelevant context. Information context and other aspects of the decision making environment that are not associated with the choice attributes are absence from choice modelling frameworks (such as Ben-Akiva and Lerman, 1985, discussed in section 2.1).

Studies of so-called 'framing effects' in a range of contexts have explored how individuals respond differentially to equivalent descriptions of the same critical information, presented in different formats. Information can be putted in a positive or negative light, emphasising choice outcomes that can be perceived as either 'gains' or 'losses', in order to focus attention either on the positive or the negative aspects of it (Hallahan, 1999; Thaler et al., 1997). Across many contexts, the impact of negatively framed information has consistently been found to be stronger than the impact of the same information framed in positive terms of the same magnitude. One of the explanations to the effects of this so-called gain/loss framing refers to the tendency for people to avoid losses (loss aversion), which guides them to a particular choice.

Loss framing can be incorporated in the design of a variety of information-based measures to promote travel behaviour change. These could include web-based journey planners, carbon calculators or 'tailored' travel information provided to individuals and households who participate a personal travel plan (Avineri and Waygood, forthcoming). Of specific interest to the context of transport and climate change is the framing of information on transport-related carbon emissions associated with alternative travel modes. As information on $\mathrm{CO}_{2}$ is not directly relevant and familiar to the individual, and might be perceived as an external cost to society rather than as a private cost to the individual, Avineri and Waygood (forthcoming) argued that it is not obvious that the framing of such information as 'gain' or 'loss' will have an effect on individual's perception, motivation or behaviour towards sustainable choices. Applying an experimental approach, they describe how loss framing could increase the differences about the mass of transport-related $\mathrm{CO}_{2}$ emissions, as perceived by survey participants. The comparison sets were based on the per passenger amounts of $\mathrm{CO}_{2}$ produced over a five mile trip by bicycle, full car, and single occupancy $4 \times 4$ (the amounts were 132g, 500g, and 3400g respectively). Emissions generated by one transport mode were semantically framed against the second transport mode of the same set, as being "lower" or "higher" (i.e. "better" or "worse") for the same journey (see figure 1). Framing the difference as a loss, nearly all participants perceived the compared travel options to be 'much different' by their emissions. However, having it framed as a gain, most of the participants did not perceive much difference between the travel options. 
Set 1 (132g against 500g)

i. $\quad$ Gain framing for comparison set 1 :

Mode $X$ produces $500 \mathrm{~g}$ of $\mathrm{CO}_{2}$ for a 5 mile trip.

The amount produced by mode $\mathrm{Y}$ is $368 \mathrm{~g}$ lower (i.e. better).

ii. Loss framing for comparison set 1 :

Mode $X$ produces $132 \mathrm{~g}$ of $\mathrm{CO}_{2}$ for a 5 mile trip.

The amount produced by mode $Y$ is $368 \mathrm{~g}$ higher (i.e. worse).

Set 2 (500g against $3400 \mathrm{~g}$ )

iii. Gain framing for comparison set 2:

Mode $X$ produces $3400 \mathrm{~g}$ of $\mathrm{CO}_{2}$ for a 5 mile trip.

The amount produced by mode $Y$ is $2900 \mathrm{~g}$ lower (i.e. better).

iv. Loss framing for comparison set 2:

Mode $X$ produces $500 \mathrm{~g}$ of $\mathrm{CO}_{2}$ for a 5 mile trip.

The amount produced by mode $\mathrm{Y}$ is $2900 \mathrm{~g}$ higher (i.e. worse).

Fig. 1. Gain and loss framing for two $\mathrm{CO}_{2}$ emissions comparison sets (Avineri and Waygood, forthcoming).

Contribution to climate change associated with travel choices can be considered a social dilemma, rather than an individual problem. This suggests that people may not have as strong a tendency to personally avoid environmental "losses" associated with transport alternatives, thus lowering the potential effectiveness of loss framing as their desire to avoid it may not be as strong as those for personal impacts. However some pro-environmental behaviours can be explained by normative goals, people tendency to "act appropriately" (Lindenberg and Steg, 2007) and their motivation to "do the right thing" (Dawnay and Shah, 2005). The findings reported in Avineri and Waygood (forthcoming) show how the effectiveness of framing in the design of environmental information might illustrate how two key principles of behavioural economics ('loss aversion' and 'doing the right thing').

Framing is only one example of how contextual design of information might be effective in influencing human behaviour. In an attempt to introduce policy makers at the UK with some of the robust effects of context on people's behaviour, and add them to the traditional policy-maker toolbox of education, regulation and incentives, the UK Cabinet Office (Dolan et al., 2010) provides detailed review and recommendations regarding nine robust influences on human behaviour and change, arranged according to the acronym MINDSCAPE (Messenger, Incentives, Norms, Defaults, Salience, Priming, Affect, Commitments, Ego). Metclafe and Dolan (forthcoming) provide a detailed explanation of these effects. 
We will now briefly illustrate some of the potential applications of other key concepts in behavioural economics to the context of sustainable travel behaviour.

Financial (dis)incentives might send the wrong message. The use of financial incentives to motivate behavioural change is advocated by economists. However, recent findings from behavioural economics suggest otherwise. For example, increased incentives can cause people to consciously think about the task, shift control of behaviour from "automatic" to less effective "controlled" mental processes, and narrow individuals' focus of attention on a variety of dimensions, including the breadth of the solution set been considered by individuals (Easterbrook, 1959, Langer and Imber, 1979; and Camerer et al., 2005, cited in Ariely et al., 2009b). Moreover, studies in behavioural economics show that when prices are not mentioned people apply social norms to determine their choices and effort (Heymen and Ariely, 2004). People natural motivation 'to do the right thing' and perform pro-social behaviours might be cancelled by other motivations where financial (dis)incentives are introduced. For example, introducing a penalty for parents who are late picking up their children from nursery increased the frequency of late arrivals (Gneezy and Rustichini, 2000). Generally, when people receive a financial incentive for performing a behaviour they would have done anyway, they do it less well if they perceive the payment as inadequate (Ariely et al., 2009a). By the same token, making "good" transport behaviour (in the contexts of travel behaviour and road safety behaviour) a matter for financial reward can discourage it. For example, penalties on illegal parking might be seen by some as a probabilistic price as a signal of market price that might substitute a social norm. Providing financial (dis)incentives to promote sustainable travel behaviours might be particularly problematic in light of the fact that many are motivated to travel in a sustainable manner by pro-environmental attitudes, values and norms. Financial incentives can crowd out feelings of civic responsibility and may actually discourage the kinds of behaviours needed to solve collective social problems such as climate change (Frey, 1997).

Default choices. People are influenced by 'defaults' set to them by choice architects. Picking 'smart' defaults is a way to nudge towards specific choices. For example, Pichert and Katsikopoulos (2008) argue that offering an environmentally friendly source of energy as a default, more people will choose to use and buy green electricities. Although 'green defaults' are relevant to travel behaviour, there is not be an obvious parallel in this context (perhaps indicating a gap in both research and policy). For example, in the context of travel information systems and personal travel plans, the more desired choices (i.e. sustainable modes such as walking, cycling or public transport, and generally - alternatives to single occupancy car use) can be presented as the default choices.

Salience. Without feedback, a behavioural change is less likely. Direct feedback on energy consumption (e.g. smart metre reading) was found to have an impact ranged from $5 \%$ to a $15 \%$ reduction in energy use (Darby, 2006). Transport-related carbon emissions are invisible to travellers; it is therefore difficult for them to associate their travel behaviour with 
environmental costs. A specific challenge travel planners are faced with is how to visualise and contextualize feedback on the environmental costs of journeys. However, so far there has been no empirical evidence as to whether salience is effective in this context.

Grass roots. Individuals are influenced by 'significant others', people in their social networks, and people who have geographical and social proximity (neighbours, work colleagues, class colleagues). This goes against the rational man paradigm which implicitly assumes individual decision making is made in a social vacuum. For example, energy bills that provide information on how energy efficient their neighbours have encouraged people to use less energy (Schulz et al., 2007). The small-scale group-based approach applied in the EcoTeams case study (Nye and Burgess, 2008) provided supportive social context that is accounted as one of its major success factors. In the analysis of social interactions between travellers facing social dilemmas, Sunitiyoso et al. (2011a, 2011b) showed the existence of strategic behaviours that follow social learning models of confirmation (reinforcing behaviour if other group members have similar behaviour) and conformity (following the majority choice in the group). If these two types of social learning are expected to exist in real life, they might be relevant in the design of 'social nudges' to change travel behaviour. Exploring car buyer perceptions of plug-in hybrid electric vehicles (PHEVs), Axsen and Kurani (forthcoming), found that conformity, alongside other mechanisms of social influence, were found to play an important role in influencing vehicle assessment and adoption behaviour. In the UK, workplace and school travel plans operate within a community which is limited in size and may encourage pro-social behaviour using 'bottom-up' approaches and social nudges. Bartle et al. (2011) explored the process of sharing travel information among commuter cyclists through an interactive, web-based service that incorporated social networking features. The results suggested that it performed not only a functional role in diffusing practical travel information, but also a social role whereby perceived in-group membership reinforced positive views of cycling as a commuter mode. Both roles were thought to offer encouragement to those who are new to cycling or new to a particular workplace.

At the time of finalising this paper (November 2011) the UK Department for Transport has published a Behavioural Insights toolkit to support the design and development of effective transport initiatives. The Behavioural Insights toolkit provides "a readily digestible and userfriendly guide to those responsible for transport policy and delivery initiatives, both within the Department and externally" (DfT, 2011). The toolkit makes links to some of the theories and evidence reviewed in this paper, and to the Cabinet Office's MINDSCAPE. This might be the first attempt of any government to suggest how behavioural insights emerging from behaviour sciences and behavioural economics in particular can be applied in the transport context to achieve policy objectives. 


\section{Challenges in implementing concepts from behavioural economics to travel behaviour research and policy making}

As evidence that travellers do not behave as complete rational behaviours is accumulating, it can be argued that the modelling of travellers' choices, and its application to planning and policy, can be better addressed by incorporating theories and insights from behavioural economics into well-established econometric frameworks in both transport and geography (e.g. Ben-Akiva and Lerman, 1985; Anselin, 2001). However, despite the need for further theoretical and empirical development of such models, researchers and practitioners should be aware of the challenges. For example, Avineri and Bovy (2008) highlight some econometric problems in modelling and estimation of prospect theory models of travel choice, such as heterogeneity and lack of consensus regarding reference point values and difficulties in setting values to other parameters. Such models pose an especially difficult challenge in a travel behaviour context because the attributes of choices can not be easily transferred to economic equivalents. To date, there has been very limited attempt to test non-parameterized models based on PT/CPT, or to examine the generalisation of parameterized forms of PT/CPT using empirical data (e.g. Xu et al., 2011).

The past two decades have seen a rapid growth in the development and implementation of voluntarily travel behaviour change programmes and soft measures, such as travel plans. Although the 'soft' elements of such programmes are largely inspired by behavioural sciences theory, and are consistent with the 'libertarian paternalism' approach that is associated with some of the thinking in behavioural economics, it might be surprising that there has been so far no systematic attempt to apply key principles from behavioural economics and cognitive psychology to the design of such measures. For example, the underlying paradigm of conventional Personal Travel Planning (PTP) is the traveller as rational decision maker who, when exposed to information about the transport system, will have increased awareness of alternative travel options and choose the option that is most beneficial to him/her. The emphasis is on providing relevant instrumental information without very much consideration of how information is presented (information context), the source of information and the medium used to disseminate the information.

A specific challenge for planners and policy makers is to develop measures that might encourage pro-social and pro-environmental travel behaviours and eliminate the social dilemma (e.g. reducing car use, congestion and $\mathrm{CO}_{2}$ emissions). Structural approaches to reduce the external costs of transport such as investment in walking and cycling infrastructure, bus priorities, high-occupancy vehicle lanes and other traffic management measures might be further supported by behaviour change initiatives that incorporate in their design principles of behavioural economics. Choice architecture and in particular 'social' nudges might be of specific relevance to programmes characterised by a 'local' context (such are the Australian approach to voluntarily travel behaviour change, typically 
involve local government and agencies representing a wide range of social and community interests, and the British experience with travel plans might make).

Increasing awareness that the behaviour of individual travellers systematically deviate from the predictions of rational models of travel behaviour is leading to recent efforts in applying insights and conceptual frameworks from behavioural economics and cognitive psychology in the development of modelling approaches, and in the design of policy measures to enable behavioural change. In the absence of a systematic analysis of 'irrational' components of travel behaviour, in light of the limited body of evidence and the lack of large-scale empirical studies to explore bounded rationality in the specific contexts of travel behaviour, they might be a general tendency among transport researchers, planners and policy makers to adopt the key principles of behavioural economics and to incorporate some of it techniques (such as choice architecture) in the design of implementation of behaviour change measures.

However, an application of insights gain from behavioural economics, and from the evidence on choice-making in non-transport contexts might not be immediate transferable to a transport context. For example, some transport studies assume the existence and significance of loss aversion among travellers. Indeed, loss aversion has been exhibited in a range of behaviours (in general and transport contexts) tested mainly in static ('one-shot') settings, with limited feedback or incentives. This pattern is well-captured by prospect theory (Kahneman and Tversky, 1979), which has been designed and tested for static choice-making. However, some recent studies have questioned this paradigm, mainly in dynamic settings (repeated decisions) that feature feedback (Erev and Barron, 2005; Avineri and Prashker, 2005; Ert and Erev, 2008). The effect of individual experience in repeated decisions does not appear to reflect loss aversion for the average individual. Therefore, effectiveness of loss framing strategies is subject to the travel making environment; it can be argued that as many travel decisions are dynamic by nature (and many of them are repeated or even routine, such as commuting) and as travellers usually obtain (mainly by own experience) feedback associated with their choices, they would be less likely to exhibit loss aversion. This illustrates that transferring insights from behavioural economics to travel behaviour could be rather challenging, as the context of choice making in transport might be different from choice making in a financial or economic environment of decision making.

Reviewing a wide range of empirical evidence from behavioural economics and cultural psychology, Levinson and Peng (2006) argue that behavioural economic research has tended to ignore the role of cultural differences in economic decision-making. They argue that most of the evidence on human (ir)rationality is based on theories and evidence developed by Western scholars, affected by culturally guided assumptions about human minds, desires and rationality. For example, studies conducted in China challenge the cultural universality of framing effects and tend to indicate that Chinese, compared with American, are less or not affected by framing (Wang, 1996 cited in Levinson and Peng, 2006). Levinson and Peng 
(2006) advocate embracing culture as an important factor in the modelling of economic decision-making. Cultural and geographic contexts are specifically relevant to the understanding of individual's behaviours associated with transport and climate change. This can be identified as one of the gaps in the implementation of behavioural economics in both general and in the specific context of transport and climate change.

\section{Concluding Comments}

This paper has sought to offer an insight into some of the challenges and opportunities associated with theory and evidence emerge from behavioural economics, its roots in other behavioural sciences, and its wider applications to a range of policy contexts. What is evident is the considerable diversity of factors that are likely to explain systematic deviations of human behaviour from the predictions of rational models, and the potential application of contextual design and other insights emerge from behavioural economics to the design of behaviour change measures and policies in transport through choice architecture and 'nudges'.

However, Avineri and Goodwin (2010) argue that one of the limitations of the 'nudge' strategy is that being designed to influence individuals' behaviour through intuitive and impulsive processes of the automatic system they do not address the fundamental problem of behavioural change. Nudges work best on unintentional/automatic behaviours within a controlled context, however they are not designed to change the decision making process of the reflective system. They do not make an objective improvement to the choice set or to the choices' attributes and utilities. Moreover, not like some of the traditional soft measures, they do not lead directly to a real change to the individual's knowledge, attitudes or values towards sustainable travel choices. It might thus be difficult to maintain and achieve long-term and sustainable behavioural change just by designing measures that are based on the nudge approach, as without promoting and maintaining sustainable travel behaviour through utilities and attitudes, their effects are likely to be cancelled. Moreover, it is not possible to control the overall context in which nudge initiatives are introduced and behavioural change achieved by choice architecture might be easily offset by unintended effects.

It seems almost self-evident that an approach which recognises boundedly rational as well as rational and planned determinants of behaviour must be able to give better predictions and better insights into how behaviour change works; policy interventions can therefore be more successful as well as less intrusive if nudge interventions are included in a package of measures to influence both the automatic and the reflective decision making systems, pulling behaviour change consistently in the same direction. The promise of behavioural economics and choice architecture might be primarily in improving the design of bigger 
initiatives, that is to add 'nudges' to improve or speed up the effects rather than as a replacement for other interventions.

The incorporation of principles and behavioural notions used in behavioural economics in travel behaviour models, and the use of choice architecture in the design of planning and policy measures, have already become subjects of professional and academic debate and undoubtedly will remain such in the future. There is a need to outline a research agenda regarding climate change mitigation, behaviour change and behaviour economics. The following is a first attempt to identify several priorities for such an agenda.

- There is a need for critical evaluation of the robustness of evidence and findings that have emerged from the study of human behaviour in decision making environments associated with economic and financial contexts to travel behaviour contexts.

- Many travel behaviour models apply stated preferences methods and use surveys in which participants make decisions based on description of the choice set rather than experience. Travel behaviours captured by stated preferences techniques might be biased towards the predictions of models assuming rational behaviour, and might not reflect choice patterns emerge from adaptive learning, feedback effects, and habitual behaviour. More research can focus on the dynamic environment of travel choice behaviour.

- Awareness of transport modellers, planners and policy makers to behavioural economics theory and evidence among is limited. Dissemination of research findings to these communities, and the incorporation of relevant contents in the curriculum of academic and professional studies in transport might help in raising the awareness to the potential use of behavioural economics in applied transport contexts.

- In mainstream modelling of travel behaviours, most of the choice attributes can relate to hedonistic goals (feeling better right now) or individual gain goals (protecting or improving one's resources) of goal framing. As normative goals might have an important role in explaining sustainable behaviours, the incorporation of attributes associated with pro-social and pro-environmental values could be further explored.

- Further investigation of contextual effects on individual perceptions and choices of sustainable travel alternatives; generally, there is a need to develop tools that might inform the design and evaluation of effective information formats.

- There is wide evidence of diversity and heterogeneity in people responses to behavioural change measures in transport. Individuals' behaviours might be traded-off in the aggregated level, leading to so-called 'asymmetric churns', making it difficult to influence, observe and monitor behaviour change. A specific attention should be given to the notion of heterogeneity in travel choice making and in travellers' responses to interventions. As interventions must look quite closely at the specifics of different people, for whom messages and services will need to be different (understanding cultural and geographic 
contexts could be specifically relevant here). Segmentation studies of travel behaviours have focused on socio-demographic and attitudes towards sustainable behaviours. One possible direction for future research is in explaining some of the heterogeneity in travel choices by behavioural economics notions (i.e. heterogeneity in loss aversion); if there is evidence of their significance in explaining, a segmentation approach might be useful in identifying which segments are more likely to change their behaviour if targeted by interventions that apply specific key principles from behavioural economics.

- Above all, it should be emphasised that the nature of travellers' choice making and the success of behaviour change measures are ultimately empirical issues. In this respect, in order to reach better descriptive models of travel choice behaviour, and to validate the effectiveness of measures design based on insights from behavioural economics, more empirical studies (including large-scale, panel and field studies in more natural environments) should be conducted, and measures designed based on behavioural economics should be systematically evaluated.

\section{Acknowledgments}

The author gratefully acknowledges the valuable comments and suggestions provided by Tim Schwanen on a draft version of the paper and the feedback provided by two anonymous reviewers.

\section{References}

M. Abou-Zeid, R. Witter, M. Bierlaire, V. Kaufmann, and M. Ben-Akiva, 2012. Happiness and travel mode switching: Findings from a Swiss public transportation experiment. Transport Policy 19(1), 93-104.

I. Ajzen, 1991. The theory of planned behavior, Organizational Behavior and Human Decision Processes 50, 179-211.

G.A. Akerlof and R.J. Shiller, 2009. Animal Spirits: How Human Psychology Drives the Economy, and Why It Matters for Global Capitalism. Princeton University Press.

J. Anable, B. Lane and T. Kelay, 2006. A review of public attitudes to climate change and transport: summary report (Research report), Department for Transport, London. http://www.dft.gov.uk/publications/review-ofpublic-attitudes-to-climate-change-and-transport-summary-report/

E. Angner and G. Loewenstein, 2010. Behavioral economics', in U. Mäki (Ed.), Handbook of the Philosophy of Science. Philosophy of Economics, Vol. 13, Elsevier, Amsterdam.

L. Anselin, 2001. Spatial econometrics. In: B. Baltagi, ed.. A companion to theoretical econometrics. Blackwell, Oxford.

T. Arentze and H. Timmermans, 2008. Social networks, social interactions, and activity-travel behavior: A framework for microsimulation. Environment and Planning B 35, 1012-1027. 
D. Ariely, 2008. Predictably irrational: The hidden forces the shape our decisions, Harper-Collins, New York.

D. Ariely, A. Bracha, S. Meier, 2009a. Doing good or doing well? Image motivation and monetary incentives in behaving prosocially. American Economic Review 99, 544-555.

D. Ariely, U. Gneezy, G. Loewenstein, and N. Mazar, 2009b. Large Stakes and Big Mistakes. Review of Economic Studies 76(2), 451-69.

N. Ashraf, C.F. Camerer, and G. Loewenstein, 2005. Adam Smith, behavioral economist. Journal of Economic Perspectives 19(3), 131-45.

S.T. Atkins, 1987. The crisis for transportation planning modelling. Transport Reviews 7(4), 307- 325.

E. Avineri, 2004. A cumulative prospect theory approach to passengers behaviour modelling: waiting time paradox revisited. Journal of Intelligent Transportation Systems 8(4) 195-204.

E. Avineri, 2006. The effect of reference point on stochastic network equilibrium. Transportation Science 40(4), 409-420.

E. Avineri and P.H.L. Bovy, 2008. Identification of parameters for prospect theory model for travel choice analysis. Transportation Research Record 2082, 141-147.

E. Avineri and P. Goodwin, 2010. Individual Behaviour Change: Evidence in Transport and Public Health. The Department for Transport, London, UK.

http://webarchive.nationalarchives.gov.uk/20100413203302/http://www.dft.gov.uk/pgr/scienceres earch/social/behaviour-changes/pdf/transport-and-health.pdf

E. Avineri, and J. N. Prashker, 2004. Violations of expected utility theory in route-choice stated preferences: The certainty effect and inflating of small probabilities. Transportation Research Record 1894, 222-229.

E. Avineri and J. N. Prashker, 2005. Sensitivity to Travel time variability: Travelers' learning perspective. Transportation Research C 13, pp. 157-183.

E. Avineri and E.O.D. Waygood, forthcoming. Applying valence framing to enhance the effect of information on transport-related carbon dioxide emissions. Forthcoming in Transportation Research A.

K. Axhausen and T. Gärling, 1992. Activity-based approaches to travel analysis: conceptual frameworks, models, and research problems. Transport Reviews 12(4), 323-341.

J. Axsen and K.S. Kurani, forthcoming. Interpersonal influence within car buyers' social networks: Applying five perspectives to plug-in hybrid vehicle drivers. Environment and Planning A.

S. Bamberg, S. Fujii, M. Friman and T. Gärling, 2010. Behaviour theory and soft transport policy measures, Transport Policy 18, 228-235.

C. Bartle, E. Avineri, and K. Chatterjee, 2011. Information-sharing and community-building: a case-study amongst commuter cyclists. The 43rd Annual UTSG (The Universities' Transport Study Group) Conference, Milton Keynes, UK.

M. Ben-Akiva and S.R. Lerman, 1985. Discrete Choice Analysis: Theory and Application to Travel Demand. The MIT Press, Cambridge, MA. 
M. Ben-Akiva, D. McFadden, K. Train, J. Walker, C. Bhat, M. Bierlaire, D. Bolduc, A. Boersch-Supan, D. Brownstone, D.S. Bunch, A. Daly, A. de Palma, D. Gopinath, A. Karlstrom and M.A. Munizaga, 2002. Hybrid choice models: Progress and challenges. Marketing Letters 13, 163-175.

E. Ben-Elia, I. Erev, and Y. Shiftan, 2008. The combined effect of information and experience on drivers' routechoice behavior. Transportation 35, pp. 165-177.

S. Cairns, L. Sloman, C. Newson, J. Anable, A. Kirkbride and P. Goodwin, 2008. Smarter choices: Assessing the potential to achieve traffic reduction using soft measures. Transport Reviews 28, 593-618.

C.F. Camerer, G. Loewenstein and D. Prelec, 2005. Neuroeconomics: How neuroscience can inform economics. Journal of Economic Literature 43(1), 9-64.

L. Chapman, 2007. Transport and climate change: A review. Journal of Transport Geography 15, 354-367.

R.B. Cialdini, 2001. Influence: Science and Practice (4th ed.). Allyn \& Bacon, Boston.

R.D. Connors and A. Sumalee, 2009. A network equilibrium model with travellers' perception of stochastic travel times. Transportation Research Part B, 43(6), 614-624

S. Darby, 2006. The Effectiveness of Feedback on Energy Consumption. A review for DEFRA on the literature on metering, billing and direct displays. http://www.eci.ox.ac.uk/research/energy/downloads/smart-meteringreport.pdf (retrieved 22.2.12).

E. Dawnay and H. Shah, 2005. Behavioural economics: seven principles for policy-makers. New Economics Foundation, London, UK.

http://www.neweconomics.org/sites/neweconomics.org/files/Behavioural_Economics_1.pdf (retrieved 22.2.12).

DfT, 2011. Behavioural Insights Toolkit. Department for Transport, London, UK. ISBN: 978-1-84864-130-3. http://www.dft.gov.uk/publications/behavioural-insights-toolkit/ (retrieved 22.2.12).

P. Dolan, M. Hallsworth, D. Halpern, D. King, and I. Vlaev, 2010. MINDSPACE: Influencing behaviour through public policy. Institute for Government. http://www.instituteforgovernment.org.uk/publications/mindspace (retrieved 22.2.12).

J.A. Easterbrook, 1959. The effect of emotion on cue utilization and the organization of behaviour. Psychological Review 66(3), 183-201.

S. Epstein, 1994. Integration of the cognitive and the psychodynamic unconscious. American Psychologist 49(8), 709-724.

I. Erev and G. Barron, 2005. On adaptation, maximization, and reinforcement learning among cognitive strategies. Psychological Review 112, 912-31.

E. Ert and I. Erev, 2008. The rejection of attractive gambles, loss aversion, and the lemon avoidance heuristic. Journal of Economic Psychology 29, 715-723.

European Environment Agency (EEA), 2011. Greenhouse gas emissions in Europe: a retrospective trend analysis for the period 1990-2008. http://www.eea.europa.eu/publications/ghg-retrospective-trend-analysis-1990$\underline{2008}$

R. Falk and A. Lann, 2008. The allure of equality: Uniformity in probabilistic and statistical judgment. Cognitive Psychology 57, 293-334. 
J.A. Fodor, 1983. Modularity of Mind: An Essay on Faculty Psychology. Bradford Books, MIT Press, Cambridge, MA.

B. Frey, 1997. A constitution of knaves crowds out civic virtues. Economic Journal 107, 1043-1053.

S. Gao, E. Frejinger, and M.E. Ben-Akiva, 2010. Adaptive route choices in risky traffic networks: A prospect theory approach. Transportation Research Part C 18(5), 727-740.

T. Gärling, 1998. Behavioural assumptions overlooked in travel-choice modelling. In: J. de D. Ortúzar, D. Hensher, S. Jara-Diaz (Eds.), Travel behaviour research: updating the state of play, Pergamon, Elsevier, Oxford, UK.

T. Gärling, R. Gillholm and A. Gärling, 1998. Reintroducing attitude theory in travel behavior research. Transportation 25, 129-146.

U. Gneezy and A. Rustichini, 2000. A fine is a price. Journal of Legal Studies 29(1), 1-18.

K.G. Goulias and K.M. Henson, 2006. On altruists and egoists in activity participation and travel: Who are they and do they live together? Transportation 33(5), 447-462.

K. Hallahan, 1999. Seven models of framing: Implications for Public relations. Journal of Public Relations Research 11(3), 205-242.

J. Heymen and D. Ariely, 2004. Effort for payment: A tale of two markets. Psychological Science 15(11), 787793.

R. Jones, J. Pykett and M. Whitehead, 2011. Governing temptation: Changing behaviour in an age of libertarian paternalism. Progress in Human Geography 35(4), 483-501.

R.-C. Jou, R. Kitamura, M.-C. Weng and C.-C. Chen, 2008. Dynamic commuter departure time choice under uncertainty. Transportation Research Part A 42(5), 774-783.

D. Kahneman and A. Tversky, 1979. Prospect Theory: An analysis of decision under risk. Econometrica 47, 263291.

R. Kitamura, S. Nakayama and T. Yamamoto, 1999. Self-reinforcing motorization: can travel demand management take us out of the social trap? Transport Policy 6, 135-145.

J. D Levinson and K. Peng, 2006. Valuing cultural differences in behavioral economics. The ICFAI Journal of Behavioral Finance 1, 32-47.

Y. Li, 2003. Evaluating the urban commute experience: a time perception approach. Journal of Public Transportation 6, 41-66.

Z. Li and D.A. Hensher, 2011. Prospect theoretic contributions in understanding traveller behaviour: a review and some comments. Transport Reviews 31(1), 97-115.

D. Laibson and R. Zeckhauser, 1998. Amos Tversky and the ascent of behavioral economics. Journal of Risk and Uncertainty 16, 7-47.

E.J. Langer and L.G. Imber, 1979. When practice makes imperfect: The debilitating effects of overlearning. Journal of Personality and Social Psychology 37(11), 2014-2024.

S. Lindenberg, and L. Steg, 2007. Normative, gain and hedonic goal frames guiding environmental behavior. Journal of Social Issues 63, 117-137. 
D.M. Liverman, 2008. Conventions of climate change: constructions of danger and the dispossession of the atmosphere. Journal of Historical Geography 35, 279-296.

D. McFadden, 1999. Rationality for Economists?, 1999. Journal of Risk and Uncertainty 19, 73-105.

R. Metcalfe and P. Dolan, forthcoming. Behavioural economics and its implications for transport. Journal of Transport Geography.

R.G. Mishalani, M.M. McCord and J. Wirtz, 2006. Passenger wait time perceptions at bus stops: Empirical results and impacts on evaluating real-time bus arrival information. Journal of Public Transportation 9(2), 89106.

M. Nye and J. Burgess, 2008. Promoting Durable Change in Household Waste and Energy Use Behaviour. A technical research report completed for the Department for Environment, Food and Rural Affairs. http://www.uea.ac.uk/env/cserge/pub/ext/evaluating ecoteams.pdf (retrieved 11.7.11).

E. Ostrom, J. Walker and R. Gardner, 1992. Convenants with and without a sword: self-governance is possible. American Political Science Review 86, 404-417.

E.I. Pas, 1990. Is travel demand analysis in the doldrums? In: P. Jones (Ed.) Developments in Dynamic and Activity-Based Approaches to Travel Analysis, pp. 3-27. Gower, Avebury, Aldershot.

D. Pichert and K.V. Katsikopoulos. 2008. Green defaults: Information presentation and pro-environmental behaviour. Journal of Environmental Psychology 28, 63-73.

L. Robbins, 1932. An Essay on the Nature and Significance of Economic Science. Macmillan London.

J.M. Rose and L. Masiero, 2010. A Comparison of the impacts of aspects of prospect theory on WTP/WTA estimated in preference and WTP/WTA Space. European Journal of Transport and Infrastructure Research 10, 330-346.

P. Salvini and E. J. Miller, 2005. ILUTE: An operational prototype of a comprehensive microsimulation model of urban systems. Networks and Spatial Economics 5(2), 217-234.

P.W. Schultz, J.M. Nolan, R.B. Cialdini, N.J. Goldsten, and V. Giskevicius, 2007. The constructive, destructive, and reconstructive power of social norms. Psychological Science 18, 429-434.

T. Schwanen and D. Ettema, 2009. Coping with unreliable transportation when collecting children: Examining parents' behavior with cumulative prospect theory. Transportation Research Part A, 43(5), 511-525.

S.H. Schwartz, 1977. Normative influence on altruism, in: L. Berkowitz, Editor, Advances in Experimental Social Psychology vol. 10, Academic Press, New York, 221-279.

M. Senbil and R. Kitamura, 2004. Reference points in commuter departure time choice: A prospect theoretic test of alternative decision frames. Intelligent Transportation Systems Journal 8, 19-31.

R. J Shiller, 2000. Irrational Exuberance. Princeton University Press.

H.A. Simon, 1956. Rational choice and the structure of the environment. Psychological Review 63, 129-138.

A. Smith, 1759. The Theory of Moral Sentiments. Republished (1981). Liberty Fund: Indianapolis.

Y. Sunitiyoso, E. Avineri, and K. Chatterjee, K., 2011a. On the potential of social interaction and social learning in modelling travellers' change of behaviour under uncertainty. Transportmetrica 7(1), 5-30. 
Y. Sunitiyoso, E. Avineri, and K. Chatterjee, K. 2011b. The effect of social interactions on travel behaviour: An exploratory study using a laboratory experiment. Transportation Research Part A 45, 332-344.

A. Taniguchi and S. Fujii, 2007. Promoting public transport using marketing techniques in mobility management and verifying their quantitative effects. Transportation 34, 37-49.

R.H. Thaler and C.R. Sunstein, 2003. Libertarian paternalism. American Economic Review 93, 175-79.

R.H. Thaler and C.R. Sunstein, 2008. Nudge: Improving Decisions about Health, Wealth and Happiness. Yale University Press, New Haven, CT.

R. H. Thaler, A. Tversky, D. Kahneman and A. Schwartz, 1997. The effect of myopia and loss aversion on risk taking: An experimental test. Quarterly Journal of Economics 112, 647-661.

L.-J. Tian, H.-J. Huang and Z.-Y. Gao, forthcoming. A cumulative perceived value-based dynamic user equilibrium model considering the travelers' risk evaluation on arrival time. Networks and Spatial Economics.

$\mathrm{H}$. Timmermans, 2010. On the (ir)relevance of prospect theory in modelling uncertainty in travel decisions. European Journal of Transport and Infrastructure Research 10(4), 368-384.

P. Timms, 2008. Transport models, philosophy and language. Transportation 35, 395-410

A. Tversky and D. Kahneman, 1974. Judgment under uncertainty: Heuristics and biases. Science 185, 11241130.

A. Tversky and D. Kahneman, 1992. Advances in prospect theory: Cumulative representation of uncertainty. Journal of Risk and Uncertainty 9, 195-230.

E. J. van de Kaa, 2010a. Prospect theory and choice behaviour strategies, review and synthesis from social sciences. European Journal of Transport and Infrastructure Research 10, 347-367.

E. J. van de Kaa, 2010b. Applicability of an extended prospect theory to travel behaviour research: a metaanalysis. Transport Reviews 30(6), 771-804.

M. Van Vugt, R.M. Meertens, and P.A.M. Van Lange, 1995. Car versus public transportation? The role of social value orientations in a real-life social dilemma. Journal of Applied Social Psychology 25, 258-278.

Viti, F., E. Bogers, and S. Hoogendoorn, 2005. Day-to-day learning under uncertainty with information provision: Model and data analysis. Presented at the 16th International Symposium on Transportation and Traffic Theory, University of Maryland, USA, July 2005.

P. Vovsha, E. Peterson and R. Donnelly, 2003. Explicit modelling of joint travel by household members: Statistical evidence and applied approach. Transportation Research Record 1831, 1-10.

X.T. Wang, 1996. Framing effects: Dynamics and task domains. Organizational Behavior and Human Decision Processes 68, 145-157.

H. Xu, J. Zhou and W. Xu, 2011. A decision-making rule for modeling travelers' route choice behavior based on cumulative prospect theory. Transportation Research Part C 19(20), 218-222. 